\title{
A parrésia em Foucault - tecimentos
}

Paulo Frazão Roberto $\dagger$ Programa Doutoral em Filosofia da Ciência, Tecnologia, Arte e Sociedade Centro de Filosofia das Ciências da Universidade de Lisboa

À minha Mãe, in memoriam.

L'éthique de la parole, dans une expérience de jour en jour renouvelée, affirme une exigence de véracité. Il s'agit de dire vrai, mais il n'y a pas de dire vrai sans être vrai.

Gusdorf

DOI $10.2478 / \mathrm{kjps}-2020-0014$

\section{Teias que a parrésia tece}

A parrésia é indubitavelmente o enredo maior do último Foucault. Com efeito, como adjectiva o próprio, trata-se de uma «noção-aranha»:

Com a noção de parrésia temos uma noção que está no entrecruzamento da obrigação de dizer verdade, dos procedimentos e técnicas de governamentalidade e da constituição da relação a si. [...] 
Digamos que esta noção é um pouco como uma noção-aranha [...]. (Foucault 2008: 44-45) ${ }^{1}$

É na parrésia que se entretece pois uma substancial parte do seu pensamento desse período, dedicado, fundamentalmente, à subjectividade ética e à verdade. Grifamos «fundamentalmente» para assinalar um ponto que nos parece de decisiva importância: a inflexão ou o deslocamento da política para a ética que ocorre no último Foucault. Tal não significa porém, como se constatará a propósito da própria noção de parrésia, que a dimensão ética passe a ser concebida como dissociada da esfera política (ética e política conjugam-se, como indiciam aliás o título e subtítulo dos dois últimos cursos no Collège de France: o governo de si $e$ dos outros). Significa antes, no âmbito de um alargamento do campo de análise que integra, correlaciona e complementa as anteriores problematizações sobre o saber e o poder, que o enfoque relativamente à obrigação de dizer verdade é agora colocado não tanto no sujeito como o que é constituído pela verdade mas antes num sujeito como um quem que se constitui e transforma a partir de um discurso verdadeiro; isto é, não tanto numa tecnologia política dos indivíduos, em dispositivos de saber-poder (como o inquérito ou o exame, por exemplo) que têm por objecto a produção «sujeitos sujeitados», mas antes nas práticas e técnicas de si, na relação ética de si a si (mas também aos outros) que possibilita a criação de modos de subjectivação relativamente livres e autónomos (como no caso, justamente, da parrésia) que se constituam como pontos de resistência a esses dispositivos de sujeição. Devemos por isso levar a sério o Foucault «intelectual específico» que considera, numa das suas raras indicações de cariz genericamente prescritivo, que "constituir uma ética do si (une éthique du soi)" é hoje "uma tarefa urgente, fundamental, politicamente indispensável”, porque "não há outro ponto, primeiro e último, de resistência ao

\footnotetext{
1 Para uma formulação similar, mas sem todavia empregar a expressão «noção-aranha», veja-se ainda Foucault 2009: 10. 
poder político a não ser na relação de si a si”. (cf. Foucault, 2001b: 241; os itálicos são nossos)

A noção de governamentalidade parece-nos particularmente ilustrativa a este respeito pois, apesar das conotações políticas da sua (primeira) formulação nos finais do período dito biopolítico, conhece na trama do último Foucault uma inflexão ética:

[...] creio que a reflexão sobre esta noção de governamentalidade não pode deixar de passar, teórica e praticamente, pelo elemento de um sujeito que seria definido pela relação de si a si. [...] parece-me que a análise da governamentalidade - isto é, a análise do poder como conjunto de relações reversíveis - deve se referir a uma ética do sujeito definido pela relação de si a si. O que muito simplesmente quer dizer que [...] relações de poder-governamentalidade-governo de si e dos outros-relação de si a si, tudo isso constitui uma cadeia, uma trama, e que é aí, em torno dessas noções, que se deve poder articular a questão da política e a questão da ética. (Foucault, 2001b: 241-242)²

No entanto, apesar das voltas, e do emaranhado que cresce, há que observar a raridade, uma primeira forma de raridade, da parrésia. O facto de ser pouco explorada, de não ser directamente reflectida, tanto pelos Antigos quanto pelos Modernos, pese embora, aqui e ali, a sua elevada operatividade. (cf. Foucault 2008: $45)^{3}$ E Foucault, como outrora (cf. Foucault 1969: 155 ss.), avança para a raridade: procura reconstituir "a lei da raridade", e a raridade como lei, no sentido em que a parrésia surge, de algum modo, como uma lei ou fundamento esquecido da filosofia ocidental.

\footnotetext{
${ }^{2}$ Quanto à referida primeira formulação da noção, mais política, cf. Foucault 2004: 111-112.

${ }^{3}$ Alude Foucault que o único tratado consagrado à parrésia que chegou até nós, e ainda assim em estado fragmentário, foi o Peri parrêsias de Filodemo de Gádara. Uma edição bilingue desses fragmentos encontra-se coligida sob o título On Frank Criticism. (cf. Philodemus 1998) 107
} 
Testemunham isso os últimos cursos no Collège de France - L'herméneutique du sujet (1982), Le gouvernement de soi et des autres (1983) e Le courage de la vérité (1984) -, ou, «entre-cursos», conferências em Toronto $(1982)^{4}$, Grenoble (1982) e Berkeley $(1983)^{5}$, sendo que estas duas últimas tomam explicitamente a parrésia como tema. Cursos ou conferências, Foucault analisa as transformações e modalidades da parrésia na Antiguidade Clássica e Greco-Romana, desde a sua primeira ocorrência em Eurípides até aos cínicos, com Sócrates, Platão, os epicuristas ou os estóicos, entre outros, de permeio. ${ }^{6}$

Tendo como base esses textos, o objectivo do presente estudo é considerar, de forma não exaustiva, algumas das principais linhas de força que se entretecem na problematização da parrésia tratada na derradeira fase do pensamento de Foucault.

\section{O que «parrésia» quer dizer}

Antes de mais, num tipo de exercício que de resto é característico da filosofia, comecemos por tentar esclarecer o que significa «parrésia». Exercício que, neste caso, tem uma justificação suplementar: trata-se de uma palavra que «fala grego»e cujo uso não é corrente no nosso léxico.

Ora, segundo a transliteração de Foucault, de um ponto de vista linguístico, «parrésia» - do grego parrêsia (forma nominal), parrêsiazein/parrêsiazeisthai (forma verbal), parrêsiastês, «aquele que usa da parrésia» - significa «dizer tudo»; parrêsiazein, pan-rêsia: de pan, 'tudo', e rêma, 'o que dizes'. (cf. Foucault 2016: 79-80)

Neste sentido, e quiçá no horizonte da verdade alêtheia (desvelamento, desocultamento, eclosão), aquele que usa da parrésia (parrêsiastês) diz a verdade,

\footnotetext{
${ }^{4}$ Cf. Foucault 2017.

${ }^{5}$ As duas últimas reunidas em Foucault 2016.

${ }^{6}$ E além. Na sua última aula no Collège de France, Foucault estende a análise da parrésia ao ascetismo do cristianismo primitivo; contudo, conforme alinhava a partir de alguns textos neotestamentários e patrísticos, estamos já claramente perante um «enviesamento» da noção. (cf. Foucault 2009: 290-309) 108
} 
não dissimula, "não oculta nada, abre o seu coração e o seu espírito a outros". (cf. Foucault 2016: 80)

O que nos deixa entrever outros sentidos, mais latos e até habituais, de parrésia: «falar francamente» (em francês, franc-parler; em inglês, free speech) ${ }^{7}$, falar sinceramente, falar livre ou verdadeiramente, «dizer-verdade», 'veridizer', 'veridição'.

No entanto, esse sentido matricial de «dizer tudo», naturalmente, não basta para apurar o que a parrésia é. Até porque abre uma «má» parrésia: aquela na imediata vizinhança do bavardage, do falar intempestiva, intemperada e/ou indiscriminadamente de não importa quem, quê, porquê, onde, quando, como; aquela que "consiste em dizer tudo o que vem ao espírito, sem nenhuma distinção, sem atenção ao que se diz”. (cf. Foucault 2016: 81) ${ }^{8}$

\section{O que é, na verdade, a parrésia}

Posto isto, que é então, na verdade, a parrésia para Foucault?

No lato horizonte do cuidado de $s i^{9}$, a «boa», séria, verdadeira ou autêntica parrésia é, a vários títulos, um modo de dizer, um veridizer. Fazendo jus à designação «noção-aranha», é uma teia de relações. É relação à verdade, dada a franqueza ou sinceridade; o 'parrésico' dá expressão ao seu carácter, diz isso que sabe e acredita ser verdadeiro (porque é verdadeiro) e não por mero artifício de persuasão retórica. É relação à vida, dado o risco que o parrésico pode correr e o

\footnotetext{
7 Embora para Foucault a expressão francesa traduza e realce melhor as conotações éticas da parrésia: "Sem chauvinismo, creio que [...] há na expressão «franc-parlen» certas conotações éticas que são muito claras, e não creio que na expressão «free speech» tenhais algo de semelhante." (Foucault 2017: 225)

${ }^{8} \mathrm{Na}$ Antiguidade, este uso pejorativo da parrésia é criticamente apontado como um dos factores da crise e do
declínio da democracia ateniense.

9 Entendido enquanto construção de um modo de ser e de viver éticos, de saber como se conduzir eticamente no governo de si e dos outros, esse horizonte do cuidado de si, «fio» geral e talvez principal em e com que a parrésia se entretece, situa-se histórica e geograficamente sobretudo na Antiguidade Clássica e Greco-Romana. Foucault considera que essa época é matricialmente marcada pela primazia do preceito, filosófico e moral, segundo o qual é preciso ocupar-se ou «cuidar de si próprio» (epimeleia heautou); sobre essa primazia, nomeadamente em relação (integradora) ao preceito délfico "conhece-te a ti próprio» (gnôthi seauton), (cf. Foucault 2001b: 4 ss.) Tal preceito expandir-se-á e disseminar-se-á, ao ponto de se tornar, nos dois primeiros séculos do período imperial romano, uma prática social que adquire uma certa dimensão cultural; sobre essa "cultura de si", do cuidado de si, veja-se, por exemplo, Foucault 1984b: 55-94.
} 
perigo a que corajosamente se expõe ao dizer a verdade: ao limite, é questão «de vida ou de morte». É relação a si ou a outro, por meio da postura crítica assumida; normalmente, o parrésico tem um estatuto inferior, é menos poderoso do que aquele a quem dirige com risco variável a sua crítica, a quem desafia com a verdade. Finalmente, é relação à lei moral, dado o exercício de liberdade e de dever envolvidos; o parrésico age de forma autónoma e altruísta, entende que dizer a verdade é um dever, o dever ético ou moral de tentar melhorar ou ajudar os outros (vulgo beneficência) e, por isso, a si próprio. (Quanto a tudo isto, cf. Foucault 2016: 80-85)

Resume Foucault no talvez mais circunspecto, compreensivo e descritivo passo sobre a parrésia:

Podemos portanto dizer que a parrésia é uma actividade verbal na qual aquele que fala estabelece uma relação particular com a verdade através da franqueza, uma certa relação a si próprio através do perigo, uma certa relação à lei através da liberdade e do dever, e uma certa relação aos outros através da crítica, crítica de si ou crítica dos outros. Mais precisamente, é uma actividade verbal na qual o sujeito exprime a sua relação pessoal à verdade, arriscando a sua vida, porque considera que é seu dever dizer a verdade a fim de tornar os outros melhores ou ajudá-los. Na parrésia, aquele que fala faz uso da sua liberdade e escolhe a verdade em vez da mentira, a morte em vez da vida e da segurança, a crítica em vez da lisonja, o dever em vez do interesse e do egoísmo. (Foucault 2016: 86)

\section{Parrésias: política e ética}

A estrutura geral da parrésia seria, então, nas suas principais características inter-relacionadas, a que acabamos de transcrever. No entanto, essa estrutura pode 
modalizar-se, estilizar-se, de vários modos. Simplificando, detectamos ao longo da Antiguidade três formas maiores de parrésia: a política, a ética e a filosófica.

A primeira forma apontada, a política, é também a primeira na ordem do tempo. A parrésia surge no contexto da constituição da democracia grega como um direito do cidadão «bem-nascido». Ao cidadão enquanto tal - desejavelmente, aos mais capazes, ao cidadão ao mesmo tempo "entre outros e acima dos outros" (cf. Foucault 2008: 313) - é reconhecido o direito de falar livre e francamente aos concidadãos no âmbito de uma participação activa no governo da pólis .

Mas dado que todos os cidadãos têm o direito de falar livremente em público, grassa um «mau» uso da parrésia, um «dizer-tudo» desregrado que se torna incompatível com a própria estrutura da democracia. Com a crise da democracia ateniense no século IV a.C., em que, no uso da «boa» ou autêntica parrésia, dizer a verdade e falar francamente pode acarretar a morte, o parrésico tende a deixar a ágora e passa a desempenhar sobretudo o papel - em contexto de regime monárquico - de «conselheiro do príncipe»: o exemplo mais célebre, e gorado, deste novo papel, que se insere na figura do que Foucault designa de pacto ‘parresiástico', é o de Platão na corte de Dionísio de Siracusa. ${ }^{10}$ Mas, seja na praça pública ou na corte, o parrésico é alguém que corre um risco, que pode muito bem ser o da sua morte, ao dizer corajosamente a verdade.

Sócrates, claro, testemunha perfeitamente essa coragem de verdade. Todavia, ao dirigir-se aos seus interlocutores, Sócrates visa, não tanto o governo da pólis, o domínio político, mas antes uma transformação individual (dos seus concidadãos e dele próprio). Fazendo uso da parrésia não na tribuna política ante uma assembleia mas na praça pública no quadro de uma relação inter-individual, Sócrates visa transformar a maneira de ser (o êthos) e de viver (o bíos) do seu interlocutor a fim de que ele possa aprender a cuidar de si próprio. Em Sócrates, cuja missão divina é

\footnotetext{
10 Sobre a caracterização dos moldes em que o pacto parresiástico se estabelece enquanto condição de um bom governo monárquico, implicando nomeadamente que o monarca «todo-poderoso» deva aceitar e não punir as verdades críticas acintosas que lhe possam ser dirigidas, veja-se, por exemplo, Foucault 2016: 120-122. 111 
a de cuidar de si e dos outros (incitar cada um a ocupar-se de si próprio), a exigência de parrésia desenrola-se sobretudo no referido horizonte do cuidado de si. ${ }^{11}$

A parrésia toma então um outro sentido, mais um sentido: ainda e sempre exigência de franqueza e verdade, mas derivada, inflectida, arriscada, sobretudo no mundo ético.

É o que reflecte Foucault, em sinopse:

[Gostaria de retomar o problema] da parrésia onde o deixei no ano passado. Tentar esquematizar um pouco uma transformação que julgo importante nessa história da parrésia: a passagem de uma prática, de um direito, de uma obrigação, de um dever de veridição definidos em relação à cidade, às instituiçõos da cidade, ao estatuto do cidadão, a um outro tipo de veridição, um outro tipo de parrésia que se definirá em relação não à cidade (a pólis), mas à maneira de fazer, de ser e de se conduzir dos indivíduos (o êthos), em relação também à sua constituição como sujeito moral. E, através desta transformação de uma parrésia orientada para e indexada sobre a pólis numa parrésia orientada para e indexada sobre o êthos, gostaria de vos mostrar hoje como se constituiu, pelo menos em alguns dos seus traços fundamentais, a filosofia ocidental como forma de prática do discurso verdadeiro. (Foucault 2009: 33)

\section{A parrésia filosófica}

Tal inflexão ética da parrésia deve-se em grande parte a "essa obra perfeitamente bela", para utilizar uma expressão de Platão (Êtifron, 13e $)^{12}$, que a filosofia é. E Sócrates, bem se sabe, é ilustre e paradigmático - tanto na maneira como viveu quanto, principalmente, na forma como morreu - a este respeito:

\footnotetext{
11 Quanto a esta missão divina atribuída a Sócrates, em que a veridição parrésica se articula com o preceito filosófico e moral epimeleia heautou, cf. Foucault 2009: 78 ss., 138 ss.

12 Cf. Platão 1993: 52.
} 
Teria eu cometido uma terrível falta se, quando os chefes que me escolhestes me colocaram em Potideia, Anfípolis ou Délio, aí tivesse ficado, correndo risco de morte e, quando o deus me deu um posto que, pelo que julguei perceber, era viver a filosofar, examinando-me a mim próprio e aos outros -, desertasse desse posto, com medo da morte ou do mais que fosse. (Apologia de Sócrates, 28e) $)^{13}$

E, salvaguardadas as devidas diferenças, esse exame de si e dos outros será ainda, no distendido horizonte do cuidado de si, obra dessa prática, mais privada e não tanto pública, da direcção de consciência no seio das escolas filosóficas (designadamente, a epicurista e a estóica) dos períodos helenístico e romano da Antiguidade.

Foucault sublinha, então, que "se assiste a um deslocamento dos lugares e das formas de exercício da parrésia”, isto é, da cena política para a cena filosófica. O que não significa que a parrésia desapareça do campo da política, que a parrésia seja como que o verdadeiro nascimento da filosofia, ou que a filosofia se reduza a ser parrésia. A parrésia é uma "inflexão do discurso, da prática e da vida filosóficas": é a livre e arriscada coragem de dizer a verdade que permite ao parrésico (filósofo), por exemplo, conduzir os outros comme il faut, que lhe permite governar pela verdade, governar de verdade, isto é, governar eticamente. O parrésico já não é tanto um cidadão político "entre outros e acima dos outros", antes um filósofo cidadão "como os outros, mas ao lado dos outros". (Quanto a tudo isto, cf. Foucault 2008: 312-314)

Parrésia filosófica, portanto. E, a bem pesar, em grande medida a filosofia antiga é uma prática parrésica. Tendo em conta as famosas Vidas de Filósofos, de Diógenes Laércio ou de Filóstrato, Foucault salientará que, no seu modo de vida ou existência, isto é, no seu êthos, em razão de determinadas escolhas (o que se aceita ou renuncia), a vida filosófica (bíos philosophikos) "é uma perpétua manifestação da

${ }^{13}$ Cf. Platão 1993: 84. Em consonância, dirá Foucault: "Creio que a morte de Sócrates funda na realidade do pensamento grego e, portanto, na história ocidental, [...] uma forma de veridição própria precisamente ao discurso filosófico, e cuja coragem deve exercer-se até à morte como uma prova de alma que não pode ter o seu lugar na tribuna pública." (Foucault 2009: 105) 
verdade" (cf. Foucault 2008: 319, 296), uma 'aleturgia' (alèthurgie). ${ }^{14}$ Viver filosoficamente é mostrar "o que é a verdade", como se à pergunta «o que é a verdade?» a filosofia respondesse, ostensivamente, com a sua própria vida, com o seu modo de vida. ${ }^{15}$ A parrésia é, por sua vez, uma forma dessa manifestação da verdade - e eventualmente, conforme Foucault parece dar a entender aqui e ali, a forma par excellence de uma vida na verdade, do bíos philosophikos como verdadeira vida (alêthês bíos). ${ }^{16}$ Como se, enfim, à pergunta «que é, na verdade, a parrésia?», se pudesse responder, de volta, sinceramente, «que a parrésia é na verdade»...

A vida filosófica é uma vida verdadeira, isto é, uma vida na e pela verdade, como outras, mas também a verdadeira vida, ao lado de outras. Uma vida de verdade que se manifesta também no modo, crítico e corajoso, como o filósofo parrésico se dirige quer aos poderosos, que governam politicamente os outros, quer

\footnotetext{
14 Sobre a relação entre aleturgia e verdadeira vida (alêthês bíos), cf. Foucault 2009: 200 ss. O conceito de «aleturgia» foi proposto no curso Du gouvernement des vivants no horizonte da problematização das relações entre subjectividade e verdade, para se referir justamente aos procedimentos pelos quais se manifesta a verdade do e no sujeito: os modos como a verdade se manifesta no sujeito, como o sujeito manifesta a verdade e como se manifesta na verdade, a verdade e a verdade de si. (cf. Foucault 2012: 8 ss.)

15 Este carácter ostensivo da aleturgia é sobretudo patente nos cínicos, onde toma uma forma mais visual que verbal: não se trata tanto da conformidade do veridizer parrésico com o êthos (como em Sócrates) mas da manifestação - ou até "exibição», escandalosa, provocadora e intolerável - da verdade na própria existência, na própria maneira de viver a vida (bíos), a sua visibilidade no corpo, nos gestos, nas vestes, etc.: "O cinismo não se contenta pois em acoplar ou fazer corresponder, numa harmonia ou numa homofonia, um certo tipo de discurso e uma vida conforme aos princípios enunciados no discurso. O cinismo liga o modo de vida e a verdade de um modo muito mais cerrado, muito mais preciso. Faz da forma da existência uma condição essencial para o dizer-verdade. Faz da forma da existência a prática redutora que vai dar lugar ao dizer-verdade. Enfim, faz da forma da existência um modo de tornar visível, nos gestos, nos corpos, na maneira de vestir, na maneira de se conduzir e de viver, a própria verdade. Em suma, o cinismo faz da vida, da existência, do bíos, o que se poderia chamar uma aleturgia, uma manifestação da verdade." (Foucault 2009: 159)

16 Porém, tal como a parrésia enquanto lei ou fundamento de algum modo esquecido da filosofia ocidental, este modo de bíos philosophikos, com que gemina, foi sendo negligenciado, perdeu preponderância: "Desde a origem da filosofia, e talvez, no fundo, até agora ainda e apesar de tudo, o Ocidente sempre admitiu que a filosofia não é dissociável de uma existência filosófica, que a prática da filosofia deve ser sempre mais ou menos uma espécie de exercício de vida. É nisso que a filosofia se distingue da ciência. Mas embora proclame ruidosamente, no seu princípio, que filosofar não é simplesmente uma forma de discurso mas também uma modalidade de vida, a filosofia ocidental - e tal foi a sua história, e tal foi talvez o seu destino progressivamente eliminou, ou pelo menos negligenciou e manteve sob tutela o problema dessa vida filosófica, de que tinha todavia postulado ao início que ela não podia ser dissociada da prática filosófica. Negligenciou cada vez mais, manteve sob tutela cada vez mais apertada o problema da vida no seu vínculo essencial à prática do dizer-verdade." (Foucault 2009: 216-217)
} 
aos homens, visando "conduzir as suas próprias condutas" no governo de si, isto é, governar eticamente. (cf. Foucault 2008: 315 ss.) ${ }^{17}$

\section{Êthos e modo de veridição do parrésico: cotejos}

Talvez eco repercutido de uma postura seminal segundo a qual o conhecimento não se dá "numa formulação única" nem "num único tipo de apreensão", e que "se não fosse vivida e reconhecida apenas por perfis toda a verdade adormeceria". (Foucault 1972: 215) Foucault remete-nos para outra perspectiva complementar de análise da parrésia. Uma análise mais comparativa e confrontadora mediante a qual procura realçar os principais traços do carácter ou êthos do parrésico - a sua figura, a sua postura ou atitude e o seu modo de veridição próprios -, cotejando-os nomeadamente com o que e quem o parrésico não é, ao que se opõe ou de quem especificamente se diferencia.

\section{Cotejo \#1: lisonjeador e retórico}

Um primeiro cotejo constitui-se entre as figuras adversas do parrésico e as do lisonjeador (ou adulador), por um lado, e do retórico, por outro.

Outra caracterização, também complementar, da parrésia, do que são digamos as suas funções mais gerais, serve de referencial para este exercício de cotejo. A parrésia, assinala Foucault, consiste num veridizer em que o parrésico põe em jogo, de forma correlacionada, princípios éticos e procedimentos técnicos, nos quais se implica a si e aos outros:

Parece-me que o termo parrésia se refere ao mesmo tempo, por um lado, à qualidade moral, à atitude moral, ao êthos se quisermos, e, por outro, ao procedimento técnico, à tekhnê, que são necessários,

\footnotetext{
17 "É aos filósofos que é preciso perguntar como devemos nos conduzir, e são os filósofos que dizem não apenas como devemos nos conduzir mas, também, como devemos conduzir os outros homens [...]. O filósofo apresenta-se pois, ruidosamente, como o único capaz de governar os homens, de governar aqueles que governam os homens e de constituir assim uma prática geral de governo em todos os graus possíveis: governo de si, governo dos outros. É quem governa aqueles que querem se governar a si próprios, e é quem governa aqueles que querem governar os outros." (Foucault 2001b: 130-131) 
indispensáveis para transmitir o discurso verdadeiro a quem dele precisa para a constituição de si próprio como sujeito de soberania sobre si e sujeito de veridição de si para si. (Foucault 2001b: 356)

Tendo em conta esta caracterização, Foucault considera que a figura do parrésico, no que concerne à sua atitude moral, ao seu êthos, se opõe directamente à da do lisonjeador, ao ponto de (des)qualificar a lisonja como a "adversária moral" da parrésia. (cf. Foucault 2001b: 357)

É na situação de uma desigual relação de poder - por exemplo, a do conselheiro na corte do príncipe - que tal oposição é particularmente patente e ilustradora.

O lisonjeador, quando perante alguém mais poderoso - o soberano -, tem um discurso falso, postiço: apresentado dissimuladamente como verdadeira expressão do seu pensamento, esse discurso nada mais é do que a repetição e reforço da opinião que o seu interlocutor tem já convictamente constituída (e quer ouvir) de si próprio. E, cortesia de cortesão que «faz a corte», o tom desse discurso é em geral sedutora e exageradamente elogioso, extrapolando ilusoriamente as supostas qualidades do soberano. Principal consequência: ao fiar-se nos fios em que é instrumentalmente entretecido e maniatado nesse discurso - nessa «conversa fiada» com a qual o lisonjeador não visa senão granjear proveitos pessoais -, o soberano (re)constrói uma imagem falsa e ilusória de si próprio, o que impede que "se conheça a si próprio como é" e, por conseguinte, que possa cuidar ou "ocupar-se de si próprio como deve". (cf. Foucault 2001b: 359)

O parrésico tem a atitude justamente contrária. Quando perante alguém mais poderoso, confronta-o com a verdade; exige a si próprio dizer a verdade em conformidade com o que sinceramente pensa. Pratica um veridizer frontal, crítico e corajoso, por vezes com risco da própria vida, que pode ser incómodo para quem o escuta, mas cujos efeitos são precisamente inversos aos da lisonja: porquanto entretecido com os fios consistentes, unificados, de verdade e sinceridade, é um 
discurso fiável que contribui para que aquele a quem é dirigido possa conhecer-se a si próprio como realmente é e, por conseguinte, possa cuidar melhor de si próprio. Porém, adverte Foucault, dado que o lisonjeador pode dissimuladamente simular a atitude do parrésico, o principal sinal distintivo fiável que permite reconhecer o verdadeiro parrésico é "a conformidade do que diz aos outros com a sua própria conduta", quer dizer, “do que diz com o que [e quem] é”. (cf. Foucault 2016: 265, nota a; Foucault 2017: 244-245) Um veridizer que se manifesta portanto na própria maneira de viver e de ser, no carácter, na constância de uma conduta em que logos e êthos coincidem.

Quanto à retórica, trata-se da "adversária técnica" da parrésia. Oposição que é todavia menos vincada e mais complexa, ambígua até, que a da lisonja. Com efeito, no horizonte da longa querela entre filosofia e retórica na Antiguidade, a parrésia é “essa espécie de retórica própria ou de retórica não-retórica que deve ser a do discurso filosófico", pelo que a retórica se perfilaria, em relação à parrésia, como “a sua adversária ou a sua parceira ambígua, mas a sua parceira técnica”. (cf. Foucault 2001b: 350,357$)^{18}$

Tal ambiguidade deve-se em grande parte ao facto de a parrésia, enquanto modo de veridizer fundamentalmente incorporado no discurso ou logos filosófico, compartilhar com a retórica a necessidade genérica de fazer uso, digamos material, das leis formais e dos recursos técnicos da linguagem:

A parrésia é essa forma necessária ao discurso filosófico, porque [...] dado que se utiliza o logos, é preciso que exista uma lexis (uma maneira de dizer as coisas) e um certo número de palavras que sejam escolhidas em vez de outras. Portanto, não pode haver logos filosófico sem essa espécie de corpo de linguagem que tem as suas qualidades próprias, a sua plástica própria e os seus efeitos, efeitos patéticos que são necessários. (Foucault 2001b: 350)

\footnotetext{
18 Num outro contexto, referir-se-á ainda à parrésia como "o grau zero da retórica". (cf. Foucault 2008: 53) 117
} 
Contudo, apesar desse denominador comum lexical, o procedimento técnico em que consiste o discurso do filósofo parrésico não é propriamente afim daquele da arte oratória do retórico. Diferença substancial desambiguadora a reter: reiterando o que já assinalámos, a parrésia é um procedimento técnico que se caracteriza principalmente por ser indissociável de uma determinada atitude ética. ${ }^{19}$

É na mui distinta relação do parrésico e do retórico com a verdade que tal diferença melhor se denuncia.

O métier do retórico consiste, grosso modo, num conjunto de procedimentos técnicos em que os elementos do discurso são urdidos com filigrana de modo a persuadir aqueles a quem se dirige. Discurso que não implica todavia uma correspondência, um vínculo, entre o que é dito e a opinião (o que pensa ou acredita) de quem o enuncia; o retórico não tem de se comprometer pessoalmente naquilo que diz. Por meio dos artifícios de um bem-dizer ornamentado e sedutor, loquaz, a roçar por vezes a lisonja ${ }^{20}$, o papel que desempenha é tão-somente o de atrair e enredar o auditório na teia de um discurso capaz de produzir efeitos «patéticos» (inculcar convicções, induzir condutas) previamente delineados. Mediante essa «fita», é esse o fito prioritário ou mesmo único que orienta o retórico, ao ponto de a questão de saber se o que é dito nesse discurso é verdade ou mentira ser relegada como inessencial. Sempre e quando os objectivos assim o determinem, a retórica é pois uma técnica ou arte do discurso ardilosamente "capaz de mentira".

Ora, ao contrário do retórico, afeito a sacrificar a verdade em prol do seu objectivo, o filósofo parrésico é neste ponto intransigente: no seu discurso a mentira é excluída, "apenas pode haver verdade", porque "onde não houver verdade não há franc-parler", parrésia. (cf. Foucault 2001b: 366) Um discurso de verdade no qual,

19 "Mas, quando se é filósofo, o que é necessário na maneira de regular esses elementos (elementos verbais que têm por função agir directamente sobre a alma) não deve ser essa arte, essa tekhnê que é a da retórica. Deve ser outra coisa que é, ao mesmo tempo, uma técnica e uma ética, uma arte e uma moral, e que se chama parrésia." (Foucault 2001b: 350)

${ }^{20} \mathrm{Em}$ última análise, existe uma certa «promiscuidade» entre lisonja e retórica na forma como instrumentalizam o discurso: "Os dois adversários (a lisonja e a retórica) estão aliás profundamente ligados um ao outro, já que o fundo moral da retórica é sempre a lisonja, e o instrumento privilegiado da lisonja é evidentemente a técnica e, eventualmente, as astúcias da retórica." (Foucault 2001b: 357) 
ademais, se manifesta um forte vínculo constituinte entre quem o enuncia e o que nele é dito: não só o parrésico expressa com sinceridade o que é o seu próprio pensamento, como ainda - por vezes arriscando a própria vida - se compromete pessoalmente no que diz, porquanto se trata de algo em que convictamente acredita. Princípio e postura que se repercutem na própria forma desse discurso. Dada a sinonímia entre verdade e franqueza, a parrésia, enquanto veridizer crítico dirigido a outrem, caracteriza-se não só por nada ocultar ou dissimular, mas também pela clareza da forma, por ser um discurso directo, transparente e despojado, sem os circunlóquios e ornamentos da retórica. O parrésico não é, decididamente, um crisóstomo.

Mas é quando nos colocamos «no lugar do outro», isto é, quando se analisam os efeitos que a retórica e a parrésia têm sobre os seus alocutários, que a referida diferença ética se torna mais notória. Quer uma quer outra são, grosso modo, formas de discurso exortativo e/ou apelativo dirigidas a outrem, que visam, de algum modo, influir no seu pensamento e na sua conduta. No caso do discurso retórico, trata-se de "instaurar um vínculo instigador, um vínculo de poder entre o que é dito e aquele a quem se dirige", de modo a obter a sua adesão, diríamos até sujeição, a objectivos que interessam sobretudo ao retórico; é essa a finalidade do seu ofício, a que não será estranho o facto de se exercer bastas vezes em contexto político. No caso da parrésia, trata-se, por sua vez, de um discurso de verdade que, devido à incómoda frontalidade crítica que o caracteriza, pode suscitar rejeição; nele arrisca-se mesmo "a possibilidade de uma ruptura de vínculo entre aquele que fala e aquele a quem se dirige" ${ }^{21} \mathrm{Um}$ veridizer portanto categórico, que pode até «ferir», mas que não é, todavia, absolutamente imperativo, impositivo: é antes uma «proposição» que deixa a cargo daquele a quem se destina a decisão de aceitar ou recusar a verdade nela contida, que confere ao seu interlocutor a liberdade de fazer dela um princípio de

21 Para o cotejo entre retórica e parrésia, nos termos aqui vertidos, cf. Foucault 2009: 14-15. 
conduta sem, com isso, diminuir a sua autonomia. ${ }^{22}$ No discurso que dirige a outrem, o parrésico, ao contrário do retórico, "não tem nenhum interesse directo e pessoal"; em consonância com o referido dever ético de beneficência, Foucault salienta que se trata de um exercício que "deve ser essencialmente comandado pela generosidade para com o outro" que "está no próprio âmago da obrigação moral da parrésia." (cf. Foucault 2001b: 369) No horizonte do cuidado de si (e dos outros), essa é a finalidade da tarefa do filósofo parrésico, o principal fio condutor que guia o seu discurso e define o seu êthos.

\section{Cotejo \#2: profeta, sábio, técnico}

A parrésia é um discurso de verdade, um veridizer, que se define pelo seu "conteúdo de verdade" e, sobretudo, pela sua "maneira de dizer verdade" (cf. Foucault 2008: 52); trata-se de uma das suas características distintivas mais fundamentais. Modo de veridição do qual a filosofia, no decorrer da referida inflexão ética na Antiguidade, "se vai apresentar como sendo detentora do monopólio". (cf. Foucault 2008: 281) E Sócrates, figura par excellence do filósofo parrésico - quer pelo seu modo de veridição, quer pela forma como manifesta a verdade na sua própria vida -, é quem melhor autentica e atesta a parrésia: a exemplaridade da sua maneira de viver, na qual logos e êthos coincidem, colocada à "prova de realidade" (l'épreuve de réalité) perante os outros, é ela própria pedra-detoque (basanos) da parrésia. (cf. Foucault 2008: 258, 340-341)

Mas se o filósofo detém o monopólio desse peculiar modo de veridição, tal não significa que o detenha de toda a verdade, de todos os discursos valorizados de verdadeiros. Existem, legitimamente, outros modos de ser ou modalidades de veridição. Segundo Foucault, na Antiguidade coexistem com a parrésia três outros modos de veridição: a profecia, a sabedoria e o ensinamento técnico. Três modos de veridição nos quais se perfilam, respectivamente, as figuras associadas do profeta,

22 Bem pelo contrário: "O objectivo da parrésia é fazer com que, num dado momento, aquele a quem dirigimos a palavra se encontre numa situação tal que não necessite do discurso do outro." (Foucault 2001b: 362) 
do sábio e do «técnico» (ou professor) com as suas características próprias, e que Foucault coteja com a figura do filósofo parrésico de modo a realçar, por outra via complementar, a diferença específica do seu modo de veridição.

Relativamente ao profeta, trata-se de alguém que não fala em nome próprio, mas em nome dos deuses; é, no fundo, um intermediário, aquele cujo discurso opera uma mediação entre os deuses e os homens, que "transmite aos homens uma verdade que vem de outro lugar”. Situado entre o presente o futuro, a função do seu discurso é a de desvelar a verdade do destino, inacessível à finitude humana. Mas o «fado» malfadado, para os homens, é que esse discurso "não desvela sem ser obscuro", é sibilino e não unívoco; o profeta, tal como o oráculo, fala por enigmas. O parrésico, pelo contrário, não só fala em nome próprio como aquilo que diz aos outros corresponde ao que é, convicta e comprometidamente, o seu próprio pensamento. E apesar de o seu discurso de verdade desvelar algo que pode contribuir para que aquele a quem se dirige cuide de si próprio devidamente, tal discurso não está fadado a desvendar o futuro; incide no presente, "levanta o véu que cobre o que é", um estado ou situação actual do seu interlocutor. Ademais, como vimos, dada a sua franqueza, trata-se de um discurso que se caracteriza por dizer a verdade da forma mais clara, directa e unívoca possível, sem véus. (cf. Foucault 2009: 16-17)

Ao contrário do profeta, o sábio fala em nome próprio, enuncia um discurso de verdade que lhe é imanente. E, nesse sentido, a sabedoria, modo de veridição importante na filosofia antiga, tem uma certa afinidade com a parrésia. Mas existem diferenças não despicientes. O sábio não se sente compelido a intervir, a transmitir ou manifestar a verdade do seu saber; é alguém que, um pouco à imagem do Heraclito eremita, se encontra habitualmente em retiro e em silêncio; fala com parcimónia, excepcionalmente: quando quer, quando interpelado por iniciativa de outrem ou quando uma situação urge. E o seu discurso, embora incida também no presente, versa principalmente sobre o ser e sobre a natureza (physis), a ordem das 
coisas e do mundo. O seu teor é geralmente teorético, por vezes abstracto, quando não mesmo enigmático. Ora, o parrésico, distintamente, é alguém que, por sua iniciativa, interpela incessantemente os outros com um discurso de verdade; esse é o seu dever, a sua responsabilidade, de modo a ajudar o seu interlocutor a conhecer-se e cuidar melhor de si próprio. Como "um soldado firme no seu posto", segundo a metáfora da Apologia, trata-se de uma tarefa a que não se pode furtar, uma missão que, à imagem de Sócrates "espécie de soldado entre os cidadãos", nunca abandona. E, à diferença do veridizer do sábio, que consiste sobretudo na formulação de princípios gerais de conduta, o veridizer do parrésico tem uma finalidade mais prática, aplicada, 'ethopoiética': tem em conta a singularidade do indivíduo a quem se dirige e a situação conjuntural concreta e específica na qual se encontra. ${ }^{23}$

Quanto ao técnico ou docente, no fundo aquele que ensina a sua tekhnê, a regular transmissão aos outros dos seus conhecimentos teóricos e práticos (savoirfaire) é característica do modo de veridição associado ao seu métier. E, nesse sentido, tal como o parrésico (e distintamente do sábio), tem um certo dever constante de veridição, de fazer chegar proveitosamente aos outros aquilo que sabe. Existe, porém, uma diferença substancial: o técnico, ao contrário do parrésico, normalmente não corre risco pessoal considerável no seu acto de veridição. Não corre nomeadamente o risco da ruptura da relação com aquele a quem dirige o seu discurso, dado que é constitutivo desse discurso, no âmbito do processo de ensinoaprendizagem, estabelecer um vínculo entre docente e discente que permite não só a passagem directa de conhecimentos de um ao outro como, numa perspectiva macrohistórica, é elo infinitesimal dessa correia de transmissão geral que "assegura a sobrevivência do saber" numa cultura. O parrésico, por sua vez e como referimos, é alguém que, ao confrontar o seu interlocutor com um discurso de verdade incómodo que pode suscitar hostilidade, arrisca não só a cessação da relação com o seu interlocutor como, ao limite, arrisca a sua própria vida. E, pese embora, o desiderato

23 Sobre este cotejo entre parrésia e sabedoria, que parafraseamos, cf. Foucault 2009: 17-19. Quanto à referência à metáfora do soldado na Apologia de Sócrates (28d), cf. Foucault 2009: 79. 
desse discurso seja, quando o interlocutor "aceita o pacto e participa no jogo da parrésia", o de "unir e reconciliar", tal só acontece após esse "momento essencial, estruturalmente necessário", que é o risco de dissensão. (cf. Foucault 2009: 24-25) A coragem da verdade é pois um traço distintivo fundamental da parrésia que, como se depreende, se exerce maioritariamente nos domínios ético e político e não tanto, ou propriamente, nos domínios científico e técnico. (cf. Foucault 2017: 226-227)

Mas o que se mostra como principal critério diferenciador é o âmbito privilegiado a que o modo de veridição do parrésico se refere ou indexa: a saber, o êthos, que considerado enquanto qualidade ou atitude moral é uma das principais características da parrésia. O que fundamentalmente permite distinguir o filósofo parrésico das outras três figuras é pois, diz Foucault, o modo como ele "põe em jogo o discurso verdadeiro do que os Gregos chamavam o êthos." (cf. Foucault 2009: 25)

Sem nunca ser caricatural, existe no entanto uma certa simplificação na maneira como são caracterizadas estas quatro figuras. Desde logo, porque elas não encerram em si, de forma estanque, os seus correspondentes modos de veridição. Alguns dos aspectos identitários das outras figuras, eventualmente de todas, podem surgir parcelarmente combinados numa das figuras, como Foucault indica a propósito do Sócrates parrésico. Embora o seu modo de veridição se distinga essencialmente do das outras três figuras, Sócrates não deixa de ter uma certa relação, por exemplo, com a função profética, uma vez que a missão divina de interpelar os outros a cuidarem de si lhe fora transmitida pelo oráculo de Delfos; tem também algumas afinidades com a figura do sábio, alguns traços em comum, como "a virtude pessoal, o autodomínio, a renúncia a todos os prazeres, a resistência perante todos os sofrimentos, a capacidade de abstrair-se do mundo"; ou até, em certa medida, com o docente, dado que, no fundo, a sua tarefa consiste em «ensinar» os seus interlocutores a cuidarem de si próprios, a se tornarem autónomos no governo de si e dos outros. (Quanto a tudo isto, cf. Foucault 2009: 26-27) 
Ora, ainda em Le courage de la vérité, no âmbito da referida inflexão ética da parrésia - em que a dimensão ethopoiética, isto é, a transformação individual do êthos através de um discurso verdadeiro, se torna o seu principal foco -, a malha de análise é alargada justamente em combinatória: a questão do êthos (a constituição ou formação moral do sujeito) é articulada com as da alêtheia (a produção da verdade) e da politeia (o exercício do poder). Foucault considera mesmo que uma determinada co-articulação entre esses três pólos, "irredutíveis e, ao mesmo tempo, irredutivelmente ligados uns aos outros" numa "relação necessária e recíproca", é idiossincrasicamente constitutiva da "própria existência de todo o discurso filosófico desde a Grécia até aos nossos dias". (cf. Foucault 2009: 62) Conforme complementa:

Porque o que faz com que o discurso filosófico não seja simplesmente um discurso científico, que [se limitaria a] definir e pôr em jogo as condições do dizer-verdade, o que faz com que o discurso filosófico, da Grécia aos nossos dias, não seja simplesmente um discurso político ou institucional, que se limitaria a definir o melhor sistema possível de instituições, e o que, enfim, faz com que o discurso filosófico não seja simplesmente um puro discurso moral que prescreve princípios e normas de conduta, é que, precisamente, a respeito de cada uma dessas três questões ele coloca ao mesmo tempo as outras duas. (Foucault 2009: 62-63)

Com base nesta combinatória própria ao discurso filosófico, Foucault elabora um outro exercício de cotejo entre os quatro modos de veridição e suas respectivas figuras, de forma a realçar mais uma vez os traços distintivos do filósofo parrésico. Expõe, designadamente, como a cada um dos modos de veridição correspondem, grosso modo, quatro atitudes filosóficas distintas na maneira como ligam, no seu discurso, as questões da alêtheia, da politeia e do êthos, isto é, em tradução simplificadora, da verdade, do poder e da ética. Quatro maneiras conectivas que não 124

Kairos. Journal of Philosophy \& Science 24, 2020 Center for Philosophy of Sciences of the University of Lisbon 
deixam de estar no mesmo diapasão dos cotejos anteriormente formulados; assim: "a atitude profética em filosofia profere o discurso da reconciliação prometida entre alêtheia, politeia e êthos"; "a atitude de sabedoria em filosofia é o discurso que procura pensar e dizer a unidade fundadora da verdade, da politeia e do êthos"; e, enfim, a atitude do técnico ou professor "em filosofia é o discurso da heterogeneidade e de separação entre alêtheia, politeia e êthos." (cf. Foucault 2009: 64)

Quanto à atitude parrésica, é aquela em que a forma como se interligam ou entretecem esses três pólos se constitui numa malha mais compacta e consistente (e, por conseguinte, será também aquela que, segundo a definição proposta por Foucault, mostra uma maior conformidade com a referida idiossincrasia que é constitutiva do discurso filosófico ocidental):

Nisso consiste o discurso e a atitude parrésicos em filosofia: é o discurso da irredutibilidade da verdade, do poder e do êthos, e, ao mesmo tempo, o discurso da sua necessária relação, da impossibilidade em que nos encontramos de pensar a verdade (a alêtheia), o poder (a politeia) e o êthos sem relação essencial, fundamental, entre eles. (Foucault 2009: 65)

\section{Parrésia e Aufklärung: o êthos filosófico como atitude crítica}

Mas, malhas que os tempos tecem, qual a eventual actualidade desse pensamento sobre a parrésia, desse pensamento antigo do qual Foucault nos oferece uma hermenêutica? Fiel à sua matriz, poderá ainda a filosofia ser um exercício viável de pensamento e, principalmente, de prática da parrésia?

Para Foucault, em Foucault, o problema pode talvez ser ponderado com outras nuances.

No primeiro livro onde analisa especificamente o pensamento antigo, faz questão de esclarecer que, tal como nos anteriores, se trata de "estudos de 
«história»" que, pese embora não sejam "trabalhos de «historiador»", consistem "num exercício filosófico". (cf. Foucault 1984a: 16-17) Ou seja, trata-se de uma incursão - ou de um détour, como indica no mesmo estudo - no pensamento antigo, um pensamento porventura relevante na actualidade, filosófica ou não, na medida em que Foucault, numa passagem com o seu quê de sibilina, não deixa de reconhecer, na "diferença que nos mantém à distância" desse pensamento, "a origem do nosso". (cf. Foucault 1984a: 14, nota 1)

Num pensador pouco atreito quer às continuidades históricas fáceis (basta lembrarmo-nos das epistemai em Les mots et les choses), quer às filosofias que vêem no tema da origem um inesgotável filão de sentido, o seu posicionamento em relação ao pensamento antigo neste exercício filosófico pode ser, como se depreende, problemático, crítico. Por conseguinte, a questão de saber se - e/ou o que - da prática parrésica subsiste ou não no que é o discurso filosófico ocidental moderno - período histórico e epistémico ao qual eventualmente ainda pertenceremos - deve ser muito bem ponderada.

Tendo em conta a posteridade histórica da filosofia ocidental, Foucault não sonega, por um lado, a inelutável diferença e os poucos pontos em comum que existem entre a filosofia antiga "como uma espécie de prática parrésica" e a filosofia moderna, "pelo menos se a tomamos tal como é apresentada actualmente, como objecto escolar ou universitário". (cf. Foucault 2008: 318) Mas considera também, por outro lado, que a parrésia é como que "a força alocutória [allocutoire]" ou exortativa da filosofia; uma força que, não obstante a sua parca e rarefeita manifestação directa, seria como que um persistente filamento presente ao longo das transformações da filosofia na sua história; história da filosofia que, em certa 
medida e de certa maneira, se poderia por isso ler ou perspectivar como "movimento e redistribuição da parrésia", como "jogo diverso do dizer-verdade". ${ }^{24}$

Ora, é na crítica, em certa postura ou atitude crítica como uma das principais características (inter-relacionadas) da parrésia tal como a descrevemos, que encontramos aquela que é talvez a fibra mais vigorosa ou resiliente desse filamento. Com efeito, no final da conferência de Berkeley, explicitamente dedicada ao tema da parrésia, Foucault declara que "o seu objectivo geral" consistiu em "fazer uma espécie de genealogia da atitude crítica na filosofia". (cf. Foucault 2016: 298) Por outras palavras, "através dessa história da parrésia na cultura antiga", o objectivo do seu exercício filosófico foi o de "fazer a análise da origem, da genealogia do que é, na nossa sociedade, aquilo que designamos a atitude crítica". (cf. Foucault 2016: 108)

É provavelmente tendo em mente esta genealogia da atitude crítica de longo remonte e de eventual estiramento, na diferença, desse papel crítico exortativo da parrésia na filosofia no decorrer da sua história, que Foucault formula as seguintes interrogações em Le gouvernement de soi et des autres:

Será que a filosofia moderna não pode ser lida, pelo menos em alguns dos seus aspectos e em algumas das suas significações mais essenciais, como um empreendimento parrésico? Não é como parrésia, muito mais do que como doutrina sobre o mundo, sobre a política, a Natureza, etc., que a filosofia europeia se inscreveu efectivamente no real e na história ou, melhor dizendo, nesse real que é a nossa história? (Foucault 2008: 321; os itálicos são nossos)

Interrogações com o seu quê de «retórico», como vemos um pouco mais adiante, após ter expendido algumas análises sobre tal problematização. Refere

24 "Creio que também se pode fazer a história da filosofia, não como esquecimento nem como movimento da racionalidade, mas como uma série de episódios e de formas - de formas recorrentes, de formas que se transformam - da veridição. Em suma, a história da filosofia como movimento da parrésia, como redistribuição da parrésia, como jogo diverso do dizer-verdade, filosofia considerada assim no que se poderia chamar a sua força alocutória." (Foucault 2008: 322) 
então, no âmbito de uma caracterização geral do "modo de ser da filosofia moderna", que entre os aspectos e as significações mais essenciais que a assemelham ao êthos ou ao "modo de ser da filosofia antiga" parrésica estão a filosofia considerada como "ascese", como "exterioridade renitente à política" e, permitam-nos realçar, como "crítica". (cf. Foucault 2008: 326)

Modo de ser (ou êthos) da filosofia moderna cujo principal referencial é, para Foucault, a Aufklärung. Considera, por isso, no âmbito da sua sui generis análise do questionamento kantiano da Aufklärung, que tal movimento do pensamento europeu moderno constitui, "para a filosofia, uma certa maneira de tomar consciência de problemas que na Antiguidade tradicionalmente eram os da parrésia", problemas esses que, de uma certa maneira, vão "reemergir". (cf. Foucault 2008: 322; o itálico é nosso) (Grifamos «de uma certa maneira» porque, bem entendido, a parrésia antiga não aparece transposta, tal qual, na moderna Aufklärung; tudo isso se dá na diferença, dá diferença. Com efeito, no modo como se redistribui e dissemina, o referido filamento exortativo da parrésia - que nem sequer é directamente reflectida na Aufklärung - assume obviamente formas e feições de acordo com a configuração da malha do discurso filosófico própria ao contexto histórico moderno onde reemerge.)

É em trecho de uma das duas versões do artigo Qu'est-ce que les Lumières? que Foucault, curiosamente sem aí nomear explicitamente a parrésia, nos parece mais esclarecedor quanto aos aspectos e às significações essenciais de problemas da parrésia que reemergem na Aufklärung. Considera, por um lado, que a Aufklärung se enraíza "num tipo de interrogação filosófica que”, aproximadamente à semelhança da parrésia, "problematiza, ao mesmo tempo, a relação ao presente, o modo de ser histórico e a constituição de si próprio [do seu êthos] como sujeito autónomo"; por outro lado, mas correlacionado, refere que o filamento ou "o fio que nos pode ligar dessa maneira à Aufklärung" é "a reactivação permanente de uma atitude" que, como se depreende pela sua subsequente explicitação, é afim à atitude 
crítica parrésica: a "de um êthos filosófico que se poderia caracterizar como crítica permanente do nosso ser histórico."25

Porque a ênfase é colocada na «re-activação», permanente, de uma atitude, crítica, Foucault, referindo-se ainda ao texto de Kant, alvitra que talvez pudéssemos "considerar a Modernidade mais como uma atitude do que como um período da história”. Sugestão que, complementa, se estriba num certo posicionamento em relação à actualidade ou ao presente que é característico dessa atitude; um posicionamento no qual, dado os seus desideratos, a tarefa do Auflkärer seria "um pouco" afim à do parrésico, cujo principal fito é a constituição e transformação do seu êthos:

Por atitude, pretendo dizer um modo de relação que concerne à actualidade; uma escolha voluntária que é feita por alguns; enfim, uma maneira de pensar e de sentir, uma maneira também de agir e de se conduzir que, ao mesmo tempo, marca uma pertença e se apresenta como uma tarefa. Um pouco, sem dúvida, como o que os Gregos chamavam um êthos. (Foucault 2001a: 1387)

Esta atitude, crítica, perspectivada como um certo posicionamento em relação à actualidade ou ao presente, insere-se no tema do que Foucault designa de uma ontologia histórico-crítica de nós próprios, e cuja elaboração conceptual problematiza sobretudo aquando da sua análise do questionamento kantiano da Aufklärung. Uma análise que incide não sobre a Crítica kantiana «propriamente dita», isto é, sobre "a questão das condições sob as quais um conhecimento verdadeiro é possível" (e que designa de "analítica da verdade”), mas que, a partir de uma problematização da Aufklärung, coloca a questão, histórico-crítica, do

\footnotetext{
25 Porque Foucault "queria sublinhar", vale talvez a pena citar o trecho in extenso: "Queria sublinhar, por um lado, o enraizamento na Aufklärung de um tipo de interrogação filosófica que problematiza, ao mesmo tempo, a relação ao presente, o modo de ser histórico e a constituição de si próprio como sujeito autónomo; por outro lado, queria sublinhar que o fio que nos pode ligar dessa maneira à Aufklärung não é a fidelidade a elementos de doutrina, mas antes a reactivação permanente de uma atitude; quer dizer, de um êthos filosófico que se poderia caracterizar como crítica permanente do nosso ser histórico." (Foucault 2001a: 1390; os itálicos são nossos)
} 
"campo actual das nossas experiências possíveis", de um "pensamento [filosófico] crítico que tomará a forma de uma ontologia de nós próprios, de uma ontologia da actualidade." (cf. Foucault 2008: 21-22) ${ }^{26}$ Uma ontologia histórica de nós próprios que, como assinala na conferência La culture de soi em Berkeley (1983), "deve analisar três conjuntos de relações: as nossas relações à verdade, as nossas relações à obrigação, as nossas relações a nós próprios e aos outros" (cf. Foucault 2015: 84); três conjuntos ou "três eixos" - que atravessam toda a obra foucaultiana - "de que é necessário analisar a especificidade e a intricação: o eixo do saber, o eixo do poder, o eixo da ética." (cf. Foucault 2001a: 1395)

Ontologia histórico-crítica de nós próprios problematizada sobretudo em relação à Aufklärung, mas que, refere Foucault, se encontra de certa maneira também genealogicamente presente na parrésia - cujo principal fito é, volte-se a frisar, a transformação individual do êthos através de um discurso verdadeiro. É mesmo no seu horizonte que inscreve, justamente, o estudo histórico da parrésia como "genealogia da atitude crítica" na sua correlação com "a genealogia da subjectividade" ocidental:

[...] a análise da parrésia faz parte do que poderia chamar a ontologia histórica de nós próprios, já que enquanto seres humanos somos capazes de dizer a verdade e de nos transformar a nós próprios, transformar os nosso hábitos, o nosso êthos, a nossa sociedade, de nos transformarmos ao dizer a verdade. (Foucault 2016: 109)

Um certo posicionamento face à actualidade inserido numa ontologia histórico-crítica de nós próprios que seria talvez um outro filamento, entretecido com o da persistente atitude crítica parrésica, que, mutatis mutandis, apareceria problematizado também e ainda na Aufklärung. Afinidade que nos parece implícita no trecho que se segue a propósito da Aufklärung:

\footnotetext{
${ }^{26}$ A propósito da décalage entre estas duas tradições críticas presentes no pensamento de Kant, veja-se ainda Foucault 2015: 82-85 e Foucault 2001a: 1506-1507. 
É preciso considerar a ontologia crítica de nós próprios, não certamente como uma teoria ou uma doutrina, nem sequer como um corpo permanente de saber que se acumula, mas antes como uma atitude, um êthos, uma vida filosófica em que a crítica do que somos é ao mesmo tempo análise histórica dos limites que nos são colocados e experiência da sua possível transposição. (Foucault 2001a: 1396)

Embora essa ontologia histórica e crítica de nós próprios resulte de uma análise arqueológica que situa a sua emergência e pertença ao sistema de pensamento moderno, o filamento genealógico da atitude crítica como êthos filosófico parece surgir aqui como um motivo transversal ao próprio pensamento ocidental, que coloca à prova esses limites históricos em que estamos situados visando a sua possível transposição. Portanto, determinação, situação histórica, social, política e epistémica, e trabalho/tarefa indefinidos de liberdade possibilidade crítica de transposição parcial dessas determinações, através da crítica e da invenção, enquanto sujeitos autónomos, de outros modos de relação à nós próprios e aos outros, outros modos de ser, de existência, de vida, de êthos. (A este propósito veja-se também Foucault 2001a: 1393) Resume Foucault:

Caracterizarei portanto o êthos filosófico próprio à ontologia crítica de nós próprios como uma experiência histórico-prática dos limites que podemos franquear, e, por conseguinte, como trabalho de nós próprio sobre nós próprios enquanto sujeitos livres. (Foucault 2001a: 1394)

O que talvez nos permita compreender agora um pouco melhor porque Foucault, ao se referir ao texto de Kant sobre a Aufklärung, cuja concepção de crítica redefine - não crítica dos limites transcendentais do conhecimento, mas crítica como ontologia histórica de nós próprios, na nossa relação ao presente, à actualidade, e como é possível transpor os limites do que nos é imposto como 
universal e necessário ${ }^{27}$-, se questione se a Modernidade onde se situa a Aufklärung não deve ser considerada, em afinidade com a parrésia, fundamentalmente como uma atitude, crítica, um êthos filosófico, e não tanto um período histórico.

Não obstante a recorrência da força exortativa da parrésia na história da filosofia e a «afiliação» genealógica da Aufklärung no seu filamento mais persistente, a atitude crítica, relembremos que tudo isso se dá na diferença, dá diferença. O próprio Foucault precisa e ressalva: "se evoco esta generalidade, não é para dizer que é preciso voltar a traçá-la na sua continuidade meta-histórica através do tempo, nem, tão-pouco, seguir as suas variações.” (cf. Foucault 2001a: 1396)

De resto, dado o decorrer da História, diferença dada e a dar a dar, é claro que o presente do saber moderno, justamente enquanto presente, presente presente e não presente passado, não pode ser o presente da Antiguidade. Distantes entre si temporalmente, o ser histórico do Aufklärer não é o do antigo parrésico, e o bíos philosophikos do antigo parrésico muito diferente daquele do moderno Aufklärer.

Diferenças que se patenteiam quando Foucault, num exercício hipotético, considera o que poderia ser na época moderna essa co-articulação entre os pólos do êthos, da alêtheia e da politeia como constitutiva da "própria existência de todo o discurso filosófico desde a Grécia até aos nossos dias”. Mantendo o cotejo entre os quatro modos de veridição e suas respectivas figuras, correspondendo a cada qual uma atitude filosófica no modo como no discurso da Modernidade se ligam esses três pólos, Foucault refere que encontramos "a modalidade do veridizer profético" (numa versão mais laica em relação ao futuro) em alguns "discursos políticos, revolucionários", a da sabedoria "numa certa modalidade do discurso filosófico" e, enfim, "a modalidade técnica de veridição" na "ciência", nas “instituições de investigação e de ensino". No que concerne à parrésia, como que se

\footnotetext{
27 Curiosamente, e sem se referir quer à Aufklärung (ou sequer a Kant), quer à parrésia (embora o âmbito histórico de problematização sejam as relações entre subjectividade e verdade na Antiguidade), é justamente esta concepção de crítica que advoga já numa conferência, em 1980, em Berkeley: "Em suma, trata-se de procurar um outro tipo de filosofia crítica; não uma filosofia crítica que procura determinar as condições e os limites do nosso conhecimento possível do objecto, mas uma filosofia crítica que procura as condições e as possibilidades de uma transformação do sujeito, da nossa própria transformação." (Foucault 2013: 37, nota b) 
encontra fragmentada, disseminada, esfiapada pelas formas modernas que assumiram os outros três modos de veridição:

Quanto à modalidade parrésica, creio justamente que, enquanto tal, desapareceu e já não a encontramos a não ser enxertada e apoiada numa dessas três modalidades. O discurso revolucionário, quando toma a forma de uma crítica da sociedade existente, desempenha o papel de discurso parrésico. O discurso filosófico, como análise, como reflexão sobre a finitude humana, e crítica de tudo o que possa exceder, seja na ordem do saber ou da moral, os limites da finitude humana, desempenha um pouco o papel da parrésia. Quanto ao discurso científico, quando se desdobra - e, no seu próprio desenvolvimento, não pode deixar de o fazer - como crítica dos preconceitos, dos saberes existentes, das instituições dominantes, dos modos de fazer actuais, joga esse papel parrésico. (Foucault 2009: 29-30; os itálicos são nossos)

Portanto, apesar das irredutíveis diferenças, o papel crítico e exortativo da parrésia filosófica, sob outra designação, continua a ser jogado na actualidade, ainda que disseminado por outras áreas do saber e actividades na nossa sociedade que não exclusivamente as do discurso filosófico:

Seja como for, creio que nas nossas sociedades, mesmo se não temos palavra para a parrésia, o papel parrésico, o que poderíamos chamar «o papel crítico», é algo muito importante, e que existe, em todo o caso, uma muito viva, uma muito forte concorrência nas nossas sociedades para o exercício dessa função de dizer a verdade de modo parrésico. Existe uma concorrência entre os movimentos religiosos, os partidos políticos, a universidade, os jornais, os meios de comunicação social; esses quatro tipos de instituições [...] pretendem, de uma certa forma, 
fazer o seu próprio trabalho e jogar igualmente o jogo parrésico. (Foucault 2016: 108)

\section{A entretecer...}

Ocorrida em pleno curso das suas análises sobre a parrésia, a morte de Foucault deixou eventualmente por entretecer o que seriam outras problematizações, a jusante, dessa noção-aranha.

Não cabe, num estudo com as limitações espaciais deste, explorar e desenvolver - nem sequer de uma forma que fosse minimamente satisfatória - o que poderiam ser essas problematizações. Ainda assim, permita-se-nos - captatio benevolentice - o exercício de alinhavar o que poderiam ser dois ou três fiapos soltos a/por entretecer...

$$
* * *
$$

Antes de mais, devemos notar que a filosofia, tal filosofia, fundamental e absolutamente parrésica, é efectiva e relativamente rara, prova (de) uma outra forma de raridade. Em abono da verdade, foram poucos os que, em rigor, tiveram a enfibratura de fazer dela uma «experiência-limite». Afinal de contas, só de um Sócrates reza a história, e poucos foram os filósofos que se arriscaram "a provar a morte uma só vez", para lembrar um verso de Shakespeare. (Julius Caesar, II. 2)28 Aristóteles serviria aqui de contrapeso, de contrapeso entre parrésia e sabedoria (que, como vimos, não coincidem necessariamente), entre coragem de vida e a devida coragem. Diz-se que, receando ser condenado - ao que parece, também por impiedade -, pesando a morte de Sócrates e o seu próprio perigo, Aristóteles decidiu «deixar» Atenas "porque não queria que os Atenienses pecassem duas vezes contra a Filosofia". (Cláudio Eliano, Varia Historia, III, 36) ${ }^{29}$ Portanto, mais amigo da

\footnotetext{
28 "Cowards die many times before their deaths; The valiant never taste of death but once." (Shakespeare 2009: 36)

29 Cf. Cláudio Eliano 1997: 169. 
verdade do que de Platão (Amicus Plato, sed magis amica veritas), mas mais amigo da vida do que da verdade... (E, na verdade, uns tantos outros - em qualquer caso, muitos mais do que aqueles que franquearam o limite - preferiram esta ou aquela forma de exílio: Descartes, Arnauld, Voltaire...)

Uma raridade que, como se viu, encontramos noutros horizontes históricos com os seus contornos próprios: em plena Aufklärung, Kant reclamará um "Sapere aude! Tem a coragem de te servires do teu próprio entendimento!" (cf. Kant 1985: 209), dando explicitamente a entender que a maioria vive, e é responsável por viver, ainda na menoridade, e no uso privado da razão, quer dizer, privada do uso (público) da razão. ${ }^{30}$ Por outras palavras, trata-se, nesta reemergênca moderna, de ter a coragem, no uso crítico público da razão, do logos verdadeiro, de falar livremente - expressão que é, simultaneamente, sinónima de parrésia e sua conditio sine qua non.

$$
* * *
$$

Nesta relação entre verdade e coragem, um outro fiapo solto, por entretecer, levar-nos-ia ainda a problematizar e perguntar o seguinte: e se dizer a verdade, corajosamente, coloca em risco a vida de outros? Diz-se a verdade ou não? Será preferível a parrésia ou a sabedoria? Deve então dizer-se sempre a verdade? E, inversamente, não poderá haver também coragem em não dizer a verdade?

Em toda esta problematização ressoa, obviamente, o conhecido texto de Kant sobre a mentira. (cf. Kant 1986: 433-441) Nele formula-se, num registo mais metaético de princípios formais universais, a injunção de se dizer sempre a verdade ou, na negativa, de nunca se mentir, duas faces da mesma moeda imperativa e categórica. Em nenhuma ocasião se justifica a mentira; independentemente de todas e quaisquer circunstâncias ou consequências, à tout prix, devemos dizer sempre a

\footnotetext{
30 Conforme precisa Foucault: "A Aufklärung não é pois apenas o processo pelo qual os indivíduos veriam a sua liberdade pessoal de pensamento garantida. Existe Aufklärung quando há sobreposição do uso universal, do uso livre e do uso público da razão." (Foucault 2001a: 1385) 
verdade - mesmo que, segundo o impactante e controverso exemplo aí apresentado, tal redunde na morte de um amigo às mãos de um criminoso.

Como se depreende, a universalidade, necessidade e rigidez de tal injunção são problemáticas, criticáveis. Antes de mais, porque não é aceitável, sem mais, sem menos, que dizer sempre a verdade seja absolutamente bom ou útil, benéfico. Com efeito, quando perante problemas concretos difíceis que, por vezes, abeiram o abismo do indecidível - por exemplo, as «situações-limite» de vida ou de morte na prática médica -, não será preferível, consequencialmente, mentir utilmente (ou por omissão), em benefício de outrem?

Questão que nos remete para o problema da articulação, coabitação ou conciliação de dois dos princípios da/na parrésia: a verdade - a veridição - e a beneficência - o dever de beneficência. Conciliação que particularmente se complexifica e pode complicar porque, no horizonte do cuidado de si antigo, o último dos princípios apontados é, simultaneamente, uma finalidade - ou mesmo $a$ finalidade - ética visada pelo parrésico: "é seu dever dizer a verdade a fim de tornar os outros melhores ou ajudá-los". O que nos leva ainda a problematizar: não obstante a injunção ética de verdade, da elevada e fundamental exigência de veridição da/na parrésia, em situações-limite concretas não prevalecerá aqui também - em analogia com a deontologia e prática médicas - o princípio/finalidade da não-maleficência (primum non nocere) ou, formulado positivamente, da beneficência?

Sem se constituir como cabal resposta ou solução desta problematização, parecem-nos existir na prática parrésica especificidades que favorecem a viabilização de uma certa concertação entre verdade e beneficência. Desde logo, porque a ética imanente à prática parrésica se diferencia sobremaneira de uma metaética formal e universal como a kantiana, a qual se predispõe a um absoluto e inflexível sacrifício da beneficência em prol da sagrada verdade. Com efeito, como referimos aquando do cotejo com o sábio, o veridizer do parrésico tem uma 
finalidade ética mais prática, aplicada, ethopoiética; a «boa» parrésia tem em conta a singularidade do indivíduo a quem se dirige e a situação conjuntural concreta e específica na qual se encontra (o porquê, onde, quando, como). Sem compactuar com a mentira, sem ocultar nada no seu discurso, nem furtar-se - como o faz o tendencialmente parcimonioso sábio - a empreender a tarefa de dizer a verdade a outrem, o veridizer do parrésico não é no entanto uma (in)consideração intempestiva que não tenha em conta, designadamente, aquela que é a sua principal finalidade: o dever de beneficência.

A noção de kairos, central no pensamento ético antigo, é particularmente ilustrativa a este respeito. Como assinala Foucault, a escolha do bom ou do oportuno momento em que se deve dizer a verdade a alguém é de decisiva importância na parrésia. O kairos é mesmo "o que define essencialmente as regras da parrésia" enquanto "prática particular do discurso verdadeiro": "regras de prudência, de habilidade" que têm em atenção "as condições que fazem com que se deva dizer a verdade em tal momento, sob tal forma, a tal indivíduo" e "somente na medida em que ele esteja apto a receber essa verdade, recebê-la no que é o melhor momento para ele." Escolha do melhor momento de dizer a verdade a outrem que requer que se tome em consideração o individuo e as suas circunstâncias, o tempo e o modo desse discurso, mas também, naturalmente, a ponderação da sua beneficente finalidade. Tal ponderação é deveras patente no "paralelismo" estabelecido na Antiguidade "entre a parrésia filosófica e a prática médica"; na parrésia, à semelhança da prática médica, o "aproveitar a ocasião" oportuna para se dizer a verdade a outrem tem uma finalidade "terapêutica", isto é, "deve permitir cuidar como convém". (cf. Foucault 2001b: 367, 371-372) ${ }^{31}$

Em suma, a parrésia filosófica consiste num discurso e numa prática lançados na verdade e pela verdade, mas pretendendo ser, fundamental e eticamente, benefício.

31 Ainda a propósito da importância do kairos na prática da parrésia, e a comparação desta à prática médica, veja-se Foucault 2016: 44-46, 225-226. 
Particularmente no horizonte do cuidado de si antigo, a parrésia filosófica é pois um discurso exortativo que visa influir, benéfica e generosamente, nos outros, no seu pensamento e na sua conduta. Porém, conforme demos a entender nomeadamente aquando do seu cotejo com a retórica, ressalve-se que esse discurso parrésico, não obstante o dever e o desígnio éticos de beneficência nele contidos, não é o missal ou recital de um imperativo categórico moral nem, tão-pouco, toma a forma de um dictatum normativo que prescreve e impõe.

Enquanto caracterizado, à semelhança do modo ser da filosofia antiga parrésica, pela "ascese", pela "crítica" e pela "exterioridade renitente à política", trata-se de uma ressalva extensível também ao modo de ser da filosofia moderna. Ambas são modos que, na sua identidade, se distinguem face à política ("a filosofia não tem que dizer à política o que [ela] tem que fazer"), face à ciência (“a filosofia não tem que separar o verdadeiro e o falso no domínio da ciência"), face ao sujeito (“a filosofia não tem por missão a desalienação [ou libertação] do próprio sujeito"). Distinção não significa, porém, demarcação absoluta: a filosofia pode dizer a verdade à política, de um modo não político, crítico, insubmisso até; pode dirigir-se à ciência quando, "no jogo dialéctico da sua própria verdade", examina as formas do "logro, do engano e da ilusão"; e não deixa de se orientar para o indivíduo na medida em que "pode definir as formas nas quais a relação a si pode eventualmente transformar-se". (cf. Foucault 2008: 325-326) A força exortativa da parrésia ao longo da história da filosofia, nomeadamente a persistência do seu papel crítico, seria assim, paradoxo ou différance, uma força que não força. A filosofia como lição de 'impoder'? Digamos que o filósofo deve pelo menos evitar padecer da Síndrome de Húbris...

Em relação à filosofia na sua matriz parrésica, diríamos, proporíamos portanto, que se trata de beneficência e autonomia. Se, por um lado, a parrésia se arrisca, digamos, de acordo com o princípio da beneficência ("é seu dever dizer a verdade a 
fim de tornar os outros melhores ou ajudá-los"), por outro, deixa vingar o princípio de autonomia. O parrésico não desempenha o papel de «tutor» - esse tutor tão criticado por Kant justamente no texto sobre a Aufklärung -, de paternalista «senhor» dos outros, de quem sabe exclusivamente o que é bom para os outros. Respeita, cultivando, a liberdade, a autonomia e a responsabilidade dos outros. Como referimos, trata-se de um aspecto da parrésia a que Foucault não foi insensível, e que, por isso, sem recital, re-citamos:

O objectivo da parrésia é fazer com que, num dado momento, aquele a quem dirigimos a palavra se encontre numa situação tal que não necessite do discurso do outro. (Foucault 2001b: 362)

Longe desse dispositivo moderno, apontado no final do primeiro volume de Histoire de la sexualité, cuja "ironia era fazer crer que se trata da nossa «libertação»" (cf. Foucault 1976: 211) (quando colocamos em discurso a verdade sobre o nosso desejo sexual), a parrésia filosófica parece-nos constituir-se como um modo de vida (êthos) que incorpora uma atitude crítica cujo dever é fazer crer que há liberdade, e cuja virtude é fazer querer que haja liberdade. Como se, nessa obra perfeitamente bela que é a filosofia, a autonomia e a liberdade fossem, no fundo, a única beneficência desejável.

$$
* * *
$$

Embora Foucault faça questão de ressalvar que não procura na ética filosófica antiga, na qual se inclui a prática parrésia, uma solução alternativa para problemas que seriam os de hoje (veja-se, por exemplo, Foucault 2001a: 1205), o modo como problematiza essa noção-aranha coloca em jogo questões importantes nos domínios da política, da ética e da filosofia que nos parecem pertinentes numa actualidade perturbadoramente marcada pela pós-verdade.

Assim, à guisa de conclusão, diríamos que a parrésia, imbricando subjectividade e verdade, é um modo de veridição, um veridizer, cuja principal 
preocupação reside não tanto na demonstração lógica da verdade enunciada quanto na relação ética do sujeito à verdade, no modo como o sujeito se constitui eticamente ao implicar-se na verdade do que diz, manifestando-a e mostrando-a na sua própria vida. Por outras palavras, o veridizer do parrésico, dado que não incide somente sobre o exame da verdade daquilo que se pensa, mas também, e fundamentalmente, como prova de si próprio como sujeito de verdade na sua vida e nas suas acções, implica eticamente o sujeito nessa verdade proferida.

Como referimos, a parrésia surge, em certo sentido, como uma lei ou um fundamento esquecido da filosofia ocidental, na qual a verdade é compreendida essencialmente no bios philosophikos, isto é, no modo de ser ou êthos filosófico. Na filosofia, na vida filosófica, no êthos filosófico, no que concerne à verdade, Foucault dá portanto a entender - talvez em contracorrente ou desalinhamento com o actual empreendimento filosófico - que na sua busca incessante existe algo que é talvez mais essencial que qualquer verdade lógica, metafísica, epistemológica: a exigência de uma vida eticamente verdadeira.

O que é a filosofia senão um modo de reflectir não sobre o que é verdadeiro e sobre o que é falso, mas sobre a nossa relação com a verdade? (Foucault 2001a: 929)

Tecimento e acontecimento...

\section{Referências}

Cláudio Eliano (1997) Historical Miscellany, edited and translated by Nigel G. Wilson, Cambridge MA/London: Harvard University Press.

Foucault, Michel (1969) L'archéologie du savoir, Paris: Gallimard.

Foucault, Michel (1972) Histoire de la folie à l'âge classique, Paris: Gallimard.

Foucault, Michel (1976) Histoire de la sexualité I. La volonté de savoir, Paris: Gallimard. 
Foucault, Michel (1984a) Histoire de la sexualité II. L'usage des plaisirs, Paris: Gallimard.

Foucault, Michel (1984b) Histoire de la sexualité III. Le souci de soi, Paris: Gallimard.

Foucault, Michel (2001a) Dits et écrits II (1976-1988), Paris: Quarto/Gallimard. Foucault, Michel (2001b) L'herméneutique du sujet - Cours au Collège de France (1981-1982), Paris: EHESS/Gallimard/Seuil.

Foucault, Michel (2004) Sécurité, territoire, population - Cours au Collège de France (1977-1978), Paris: Gallimard/Seuil.

Foucault, Michel (2008) Le gouvernement de soi et des autres - Cours au Collège de France (1982-1983), Paris: Gallimard/Seuil.

Foucault, Michel (2009) Le courage de la vérité. Le gouvernement de soi et des autres II - Cours au Collège de France (1983-1984), Paris: EHESS/Gallimard/ Seuil.

Foucault, Michel (2012) Du gouvernement des vivants - Cours au Collège de France (1979-1980), Paris: EHESS/Gallimard/Seuil.

Foucault, Michel (2013) L'origine de l'herméneutique de soi - Conférences prononcées à Dartmouth College (1980), Paris: Vrin.

Foucault, Michel (2015) Qu'est-ce que la critique? suivi de La culture de soi, Paris: Vrin.

Foucault, Michel (2016) Discours et vérité précédé de La parrêsia, Paris: Vrin.

Foucault, Michel (2017) Dire vrai sur soi-même - Conférences prononcées à l'Université Victoria de Toronto (1982), Paris: Vrin.

Gusdorf, Georges (1998) La parole, Paris: Quadrige/PUF. 
Kant, Immanuel (1985) “Réponse à la question: qu'est-ce que les Lumières?”, in Euvres philosophiques II. Des Prolégomènes aux écrits de 1791, trad. Heinz Wismann, Paris: Gallimard, pp. 209-217.

Kant, Immanuel (1986) "Sur un prétendu droit de mentir par humanité", in Euvres philosophiques III. Les derniers écrits, trad. Luc Ferry, Paris, Gallimard, pp. 433-441.

Philodemus (1998) On Frank Criticism, trad. David Konstan et al., Atlanta: Scholars Press.

Platão (1993) Êtifron, Apologia de Sócrates, Críton, trad. José Trindade Santos, Lisboa: Imprensa Nacional - Casa da Moeda.

Shakespeare, William (2009) Julius Caesar, edited by John Dover Wilson, Cambridge, Cambridge University Press. 